\title{
Cross-Roll Flow Forming of ODS Alloy Heat Exchanger Tubes For Hoop Creep Enhancement
}

\section{Quarterly Technical Progress Report \\ January $1^{\text {st }} 2006-$ March $31^{\text {st }} 2006$}

\author{
Principal Investigator:
}

Bimal K. Kad

Department of Structural Engineering

University of California-San Diego, La Jolla, CA 92093-0411

Tel: (858) 534 7059; Fax: (858) 534-6373; e-mail: bkad@ucsd.edu

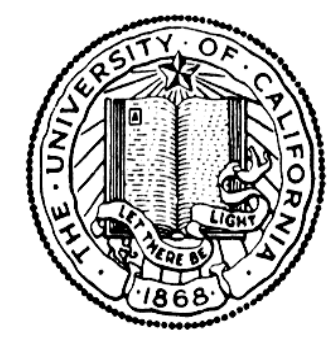

Issue Date April $14^{\text {th }} 2006$

National Energy Technology Laboratory Contract Award: DE-FC26-03NT41985

For

Development of Technologies and Capabilities for Developing Coal, Oil and Gas Energy Resources 
This report was prepared as an account of work sponsored by an agency of the United States Government. Neither the United States Government nor any agency thereof, nor any of their employees, makes any warranty, expressed or implied, or assumes any legal liability or responsibility for the accuracy, completeness, or usefulness of any information, apparatus, product, or process disclosed, or represents that its use would not infringe privately owned rights. Reference herein to any specific commercial product, process, or service by trade name, trademark, manufacturer, or otherwise, does not necessarily constitute or imply its endorsement, recommendation, or favoring by the United States Government or any agency thereof. The views and opinions of authors expressed herein do not necessarily state or reflect those of the United States Government or any agency thereof. 


\title{
Cross-Roll Flow Forming of ODS Alloy Heat Exchanger Tubes For Hoop Creep Enhancement
}

\begin{abstract}
Mechanically alloyed oxide dispersion strengthened (ODS) Fe-Cr-Al alloy thin walled tubes and sheets, produced via powder processing and consolidation methodologies, are promising materials for eventual use at temperatures up to $1200^{\circ} \mathrm{C}$ in the power generation industry, far above the temperature capabilities of conventional alloys. Target end-uses range from gas turbine combustor liners to high aspect ratio (L/D) heat exchanger tubes. Grain boundary creep processes at service temperatures, particularly those acting in the hoop direction, are the dominant failure mechanisms for such components. The processed microstructure of ODS alloys consists of high aspect ratio grains aligned parallel to the tube axis, a result of dominant axial metal flow which aligns the dispersoid particles and other impurities in the longitudinal direction. The dispersion distribution is unaltered on a micro scale by recrystallization thermal treatments, but the high aspect ratio grain shape typically obtained limits transverse grain spacing and consequently the hoop creep response. Improving hoop creep in ODS-alloy components will require understanding and manipulating the factors that control the recrystallization behavior, and represents a critical materials design and development challenge that must be overcome in order to fully exploit the potential of ODS alloys.

The objectives of this program are to 1) increase creep-strength at temperature in ODS-alloy tube and liner components by $100 \%$ via, 2) preferential cross-roll flow forming and grain/particle fibering in the critical hoop direction. The research program outlined here is iterative in nature and is intended to systematically i) examine and identify post-extrusion forming methodologies to create hoop strengthened tubes, which will be ii) evaluated at 'in-service' loads at service temperatures and environments.

In this tenth quarter of performance, program activities are continued for Tasks 2, 3 and 4 and are reported herein. Two sets of MA956 tubes rotary cross-rolled at rolling angles of $\beta=2^{\circ}$ and $8^{\circ}$ and two sets of flow formed and recrystallised tubes are being evaluated under hoop creep conditions in air. The flow formed materials exhibit superior performance than ever recorded previously. These samples are at various stages of creep testing and evaluation in Task 4 . The creep rig upgrade for testing at $1000^{\circ} \mathrm{C}$ and above is near completion. Reduced test times at accelerated temperatures will allow for additional testes to be conducted resulting in overall robust creep data statistics. The creep performance enhancement in cross-rolled MA956 material samples versus the base creep property is elucidated. The Larsen-Miller parameter for the improvised thermomechanical processing now exceeds 52. At least 2-3 orders of magnitude of improvement in creep rates/day are demonstrated for the cross-rolled samples versus the base reference tests.
\end{abstract}




\title{
Cross-Roll Flow Forming of ODS Alloy Heat Exchanger Tubes For Hoop Creep Enhancement
}

\author{
Table of Contents
}

1. Executive Summary 1

2. Experimental Task Structure 3

3. Experimental Program Activity 3

4. Results and Discussion 9

5. Conclusions 9

$\begin{array}{lr}\text { 6. References } & 10\end{array}$ 


\section{$\S 1$. Executive Summary}

Mechanically alloyed oxide dispersion strengthened (ODS) ferritic alloys based on FeCrAl and intermetallic $\mathrm{Fe}_{3} \mathrm{Al}$ alloys are promising materials for high-temperature, high-pressure tubing, liner and shell applications on account of their creep strength at very high temperatures and excellent corrosion resistance in oxidizing, oxidizing/sulphidizing and oxidizing/chlorinating environments compared to available high-temperature alloys. Requirements for such a combination of properties are found in advanced systems being developed for utilization of fossil fuels, such as the DOE's Vision 21 and FutureGen programs and in improved gas turbines being developed for power generation.

The creep strength of conventional high-temperature alloys decreases rapidly with increasing temperature, as shown in Fig. 1, since the thermodynamic stability of the various available strengthening phases also decreases with increasing temperature ${ }^{1}$. Also shown in Fig. 1 is the significant increase in temperature capability afforded when a dispersion of inert oxide particles is used as the strengthening phase. A major feature of oxide dispersion-strengthened alloys is that the most successful route for their preparation appears to involve powder metallurgical processing ${ }^{2-6}$. Further, the critical need to maintain the fine size, volume fraction, and uniform distribution of the oxide particles in the alloy matrix, as well as the need to develop specific grain shapes, results in some significant differences in alloy fabricability and in the application of joining procedures, compared to conventional cast and wrought alloys. Hence, while ODS alloys offer a significant increase in temperature capability, they have a limited formability envelope, their mechanical properties are very anisotropic, and they cannot be joined by conventional fusion welding processes. Thus, the exploitation of the full capabilities of ODS alloys is limited until these critical hurdles are addressed and overcome.

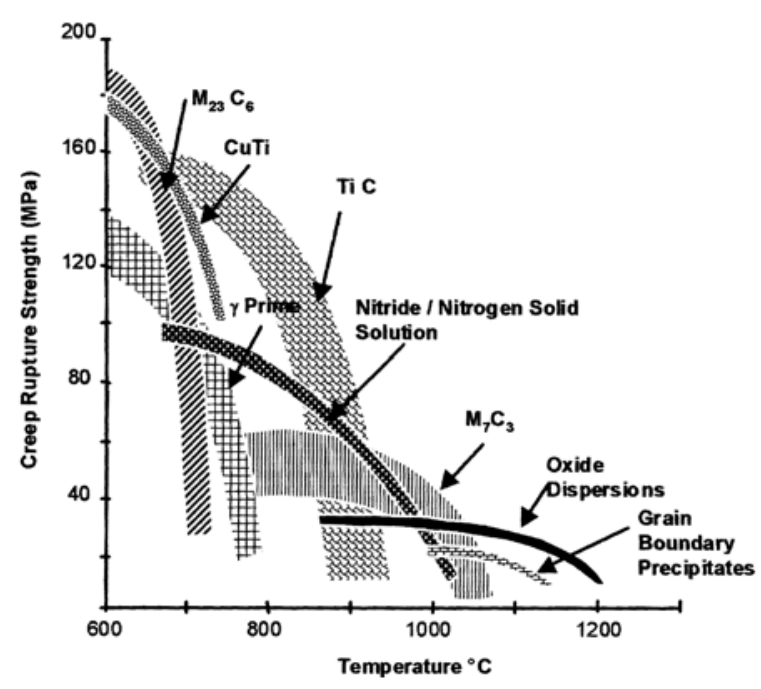

Figure 1. The creep performance envelope as a function of strengthening phase [1].

Our current program target is envisaged as a demonstration of the applicability of ferritic and $\mathrm{Fe}_{3} \mathrm{Al}$-based ODS alloys in the high temperature heat-exchanger tubing as proposed under the proposed DOE's Advanced Power System program metrics, intended to sustain internal pressures $(\mathrm{P})$ of up to $1000 \mathrm{psi}$ at service temperatures of $1000-1200^{\circ} \mathrm{C}$. Within the framework of this target application, the development of suitable mechanically alloyed ferritic $\mathrm{FeCrAl}$ and intermetallic $\mathrm{Fe}_{3} \mathrm{Al}$ alloy materials and processes must strive to deliver a combination of high mechanical strength at temperature and prolonged creep-life in service. Such design requirements are often at odds with each other as strengthening measures severely limit the asprocessed grain size detrimental to creep life. The extrusion consolidation processes currently employed cause material flow in the longitudinal direction, resulting in extreme dispersoid and powder surface impurity fibering in the axial direction in ODS materials. Thus, elongated grains are produced aligned parallel to the longitudinal direction, with a fine grain spacing in the hoop direction. The basic problem of limited hoop creep is illustrated in Figure 2a,b within the context of the existing underlying grain structure. Fortunately ODS-alloys do exhibit intrinsic creep 
strength sufficient to meet design requirements albeit that this performance is only exhibited in the longitudinal direction. Ultimate failure in transverse (hoop) creep involves creep cavity concentration, Figure $2 \mathrm{~b}$, which strongly depends on the dominant grain boundary orientation with respect to the loading axis, Figure 4 . Such fibering, unless altered by post-flow forming, is expected to thwart attempts to arrive at the large transverse grain size ${ }^{3,8}$ considered essential for improved creep performance in the hoop direction. Clearly what is required is to devise a means of effecting material flow in directions other than longitudinal that would reorient the primary fibering axis of dispersoids and impurities in the hoop direction.

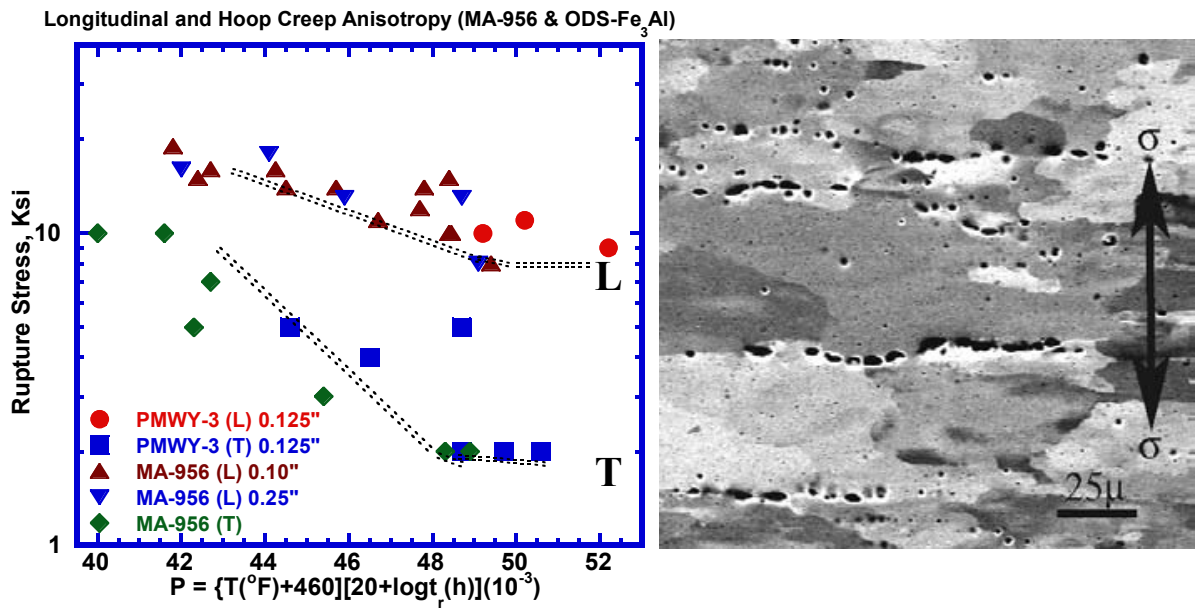

Figure 2. Longitudinal (L) vs. transverse (T) creep anisotropy in $\mathrm{Fe}_{3} \mathrm{Al}$ (PMWY3) and MA-956 tubes._b) Creep cavitation observations in hoop creep loading tests.

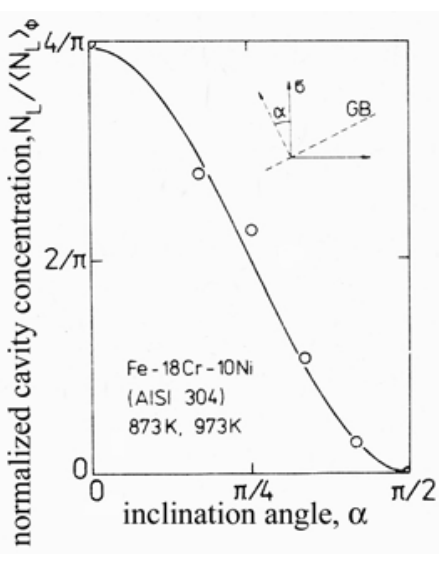

Figure 3. Creep cavity density as $f_{n}(\mathrm{~GB}$ orientation $)$ with respect to the loading axis [7].

Thus, our research objective is to modify tube-processing methodologies by incorporating cross-roll forming to create the underlying microstructure that will meet or exceed the design 'inservice' creep-life requirements of such ODS-alloy heat exchanger tubes. We are examining microscopic, microstructural and morphological issues with a view to addressing optimum material design for macroscopic components for a well prescribed 'in-service' loading criteria. This quarterly report summarizes our research activity up to the tenth quarter of performance period of January $1^{\text {st }} 2006$ - March $31^{\text {st }} 2006$. For the benefit and clarity of presentation, these reports are cumulative in order of submission.

In this quarterly performance period program work is continuing in Tasks 3 and 4. In Task 3, the capital equipment acquisition and installation at UCSD is complete. Additional hot crossrolling trials of tube samples conducted at $\beta=2^{\circ}$ and $8^{\circ}$ rolling angle were reported previously. These tubes have been recrystallized and creep test specimens have been spark machined and await creep testing as the rigs are upgraded. Initial creep test results of modified MA956 tubes of Task 2.1 are reported and compared with baseline creep performance data. The enhanced performance of cross-rolled MA956 is evident and consistent with the earlier ODS-Fe ${ }_{3} \mathrm{Al}$ enhancements ${ }^{8}$ processed similarly. A revised thermo-mechanical process is applied to the ambient temperature flow-formed tubes. This revision has produced additional hoop creep strengthening with Larsen Miller parameter exceeding 52 as reported herein. Such creep performance improvements require that test temperatures be incremented to keep the testing regime short while still yielding valuable results. Current creep rigs are being retrofitted with new pull rods and furnace hardware to conduct testing at $1000^{\circ} \mathrm{C}$ and higher. This hardware upgrade is near completion and testing is being resumed sequentially. 


\section{§ 2. Experimental Task Structure}

The experimental work reported here is described in the context of the task structure outlined below. For the duration of this program activity through September $30^{\text {th }} 2006$ and required quarterly reporting we will refer to this task structure for clarity and precise reference.

Task 1: Extrusion Consolidations, Tube and Sheet Forms: Completed

1.1 ODS-Powder materials - milling studies, impurity evaluation

1.2 Annular ODS-Alloy tube and sheet extrusions

Task 2: Rolling Studies for Optimum Fibering: Initiated \& Continuing

2.1 Single vs. cross-rolling evaluation, Parametric studies

2.2 Correlate cross-rolling strains and overall grain re-orientation

Task 3: Post-Extrusion Cross-Roll Rolling of ODS-tubes \& shells: Initiated \& Continuing

3.1 Helical/cross rolling for grain fibering

3.2 Computer model verification for torsional flow predictions

Task 4: Microstructure and Creep Performance Evaluation: Initiated \& Continuing

4.1 Recrystallization annealing: static and gradient

4.2 Microstructure characterization \& evaluation

4.3 Transverse creep and stress-rupture response

\section{§ 3. Experimental Program Activity}

Task 2.1: Single vs. cross-rolling evaluation, parametric studies: Flat sections of initial uniaxially rolled/extruded coupons to be cross-rolled via parametric evaluations of cross-grain fibering of the underlying grain structure.

Materials produced in Task 1.1 and 1.2 were sectioned and examined for microstructural details. No recrystallization was observed in either alloy materials as a result of this $900^{\circ} \mathrm{C}$ thermal-mechanical treatment. This flattened strip is the required material for the initial matrix of parametric cross-rolling studies. Based on the post-forging microstructural evaluation, and in the interest of narrowing experimental windows, all further cross-rolling studies are to be conducted at $900^{\circ} \mathrm{C}$. Residual curvature in the forge-flattened specimens was eliminated via subsequent rolling as described here. Three separate rolling schemes were employed: 1) Rolling longitudinally in 0.01 " steps till the sample was measurably flat, 2) Rolling transversely to the tube axis in 0.01 " steps till the sample was measurably flat, and 3) Rolling transversely to effect a net $20-25 \%$ thickness reduction in the starting wall thickness. In the rolling schedule 3 , this large deformation was accomplished in steps of $4-5 \%$ reduction per pass with the sample reheated to $900^{\circ} \mathrm{C}$ for 15 minutes in the air furnace. The rolled flat samples are removed from their stainless steel wraps and prepared for the recrystallization treatments. Additional levels of (cross-rolling) strains are evaluated iteratively on an as needed basis. The cross-rolled specimens are recrystallized to create abnormal grain growth in such ODS-alloy coupons. The heat 
treatments are 1 -hour at $1200^{\circ} \mathrm{C}$ in air for $\mathrm{ODS}-\mathrm{Fe}_{3} \mathrm{Al}$ and a 1 -hour at $1375^{\circ} \mathrm{C}$ in air for $\mathrm{FeCrAl}$ (MA956). Microstructures reveal elongated grain shapes in the transverse orientation only for the sample cross-rolled $20-25 \%$ in the transverse orientation. It is likely that surface layers are affected in rolling schedule 1 and 2 but no changes are perceptible at the optical resolution level.

Task 3: Cross-Roll Rolling: As part of this task UCSD proposed to purchase and install a rotary cross-rolling set up for all cross-rolling operations of MA956 and ODS-Fe ${ }_{3} \mathrm{Al}$ tubes under this program and any future needs. Figure 4 shows a Medart size ' 0 ' straightener that was purchased, reconditioned and installed at UCSD. The size ' 0 ' machine is capable of processing rod and bar in the size range of $1 / 4 "-1 \frac{1}{2}$ " and tubes in the size range $1 / 4 "-2 "$. The machine is powered by a $30 \mathrm{HP}$ motor is suitable to perform cross-rolling operations at near ambient temperatures in MA956 alloys. The current roll configuration is concave-convex pair that needs to be retrofitted to convex-convex pair. Machine diagrams for this concave-convex conversion are in process. Initial efforts are on existing geometry on dummy 2" OD carbon steel tubes. By downsizing the roll diameter, we expect to cross-roll 21/2" OD tube.

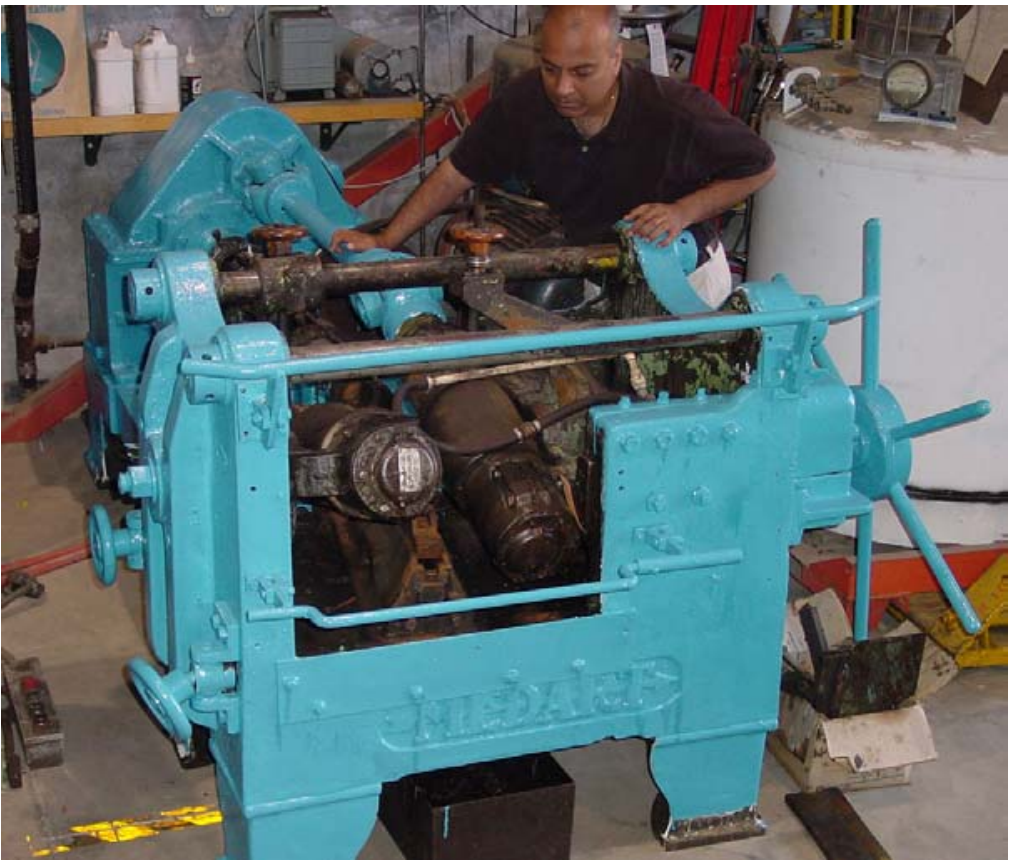

Figure 4 Cross-Rolling equipment currently installed at UCSD. The equipment is capable of rolling up to $1-1 / 2$ " bar/rod and up to $2-1 / 2$ " diameter alloy tubing in a continuous fashion

Initial cross-rolling trial experiments are performed employing two main variables. a) Rolling pressure and $b$ ) the rolling angle $(\alpha)$. The machine class and the size of the power plant turning the rolls under pressure dictate rolling pressure. The rolling angle provides the force bifurcation into the normal pressure component and the translation component affecting the movement of the tube through the roll gap geometry. Figure 5 describes the process, which is used in seamless tube manufacturing of conventional alloys. The rolls are set obliquely to each other and are inclined at small but equal angles $(\alpha)$ to the tube feed axis $(\mathrm{z})$. The surface velocity of the roll $\left(\mathrm{V}_{t}\right)$ at any material contact point is decomposed into
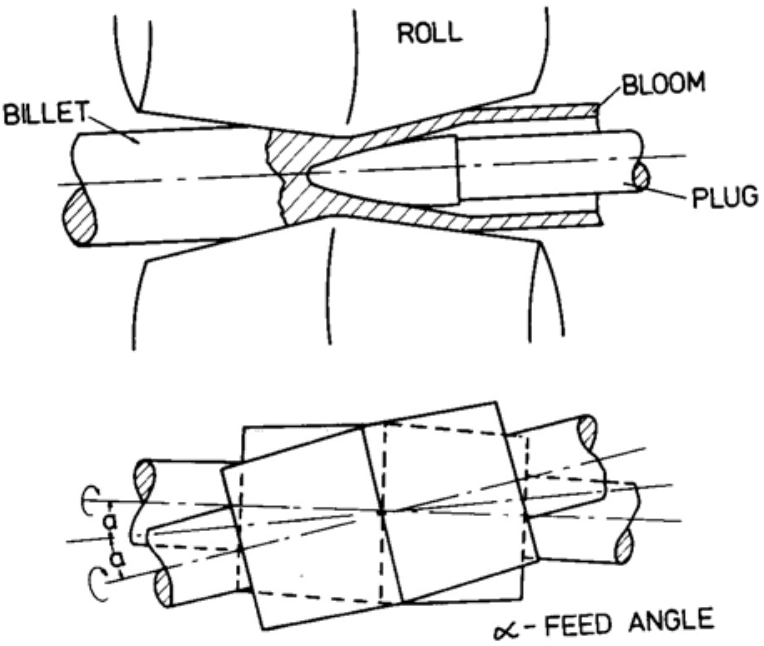

Figure 5. Tube cross-rolling schematic. The surface inclination of the rolls and the feed angle $\alpha$ dictate the overall circumferential strain and torsion. $\mathrm{V}_{t z}$ in the longitudinal direction, and $\mathrm{V}_{t \theta}$ in the circumferential direction, as given by: 
$\mathrm{V}_{t z}=\mathrm{V}_{\mathrm{t}} \sin \alpha=\omega \mathrm{R}_{\omega \mathrm{z}} \sin \alpha$

$\mathrm{V}_{t \theta}=\mathrm{V}_{\mathrm{t}} \cos \alpha=\omega \mathrm{R}_{\omega z} \cos \alpha(2)$

where $\omega=$ angular velocity of the rolls, and $R_{\omega z}$ is the roll radius at the section of interest. The hollow tube is subjected to the action of frictional traction forces, whereby the axial component produces the forward movement of the tube, and the tangential component produces cross-rolling and is responsible for its torsional rotation ${ }^{13}$.

Two separate rolling angles of $2^{\circ}$ and $8^{\circ}$ were attempted for 12 " long section of MA956 tube cross-rolled at $900^{\circ} \mathrm{C}$. A total of 6-8 passes are given through the rolls reheating the tube after each pass for 10 minutes. Note that precise measurements of rolling pressure are not possible but the roll gap and subsequent roll gap increments are kept consistent over the series of experiments performed. Figure 6 shows the end view of the tube walls after the $\beta=2^{\circ}$

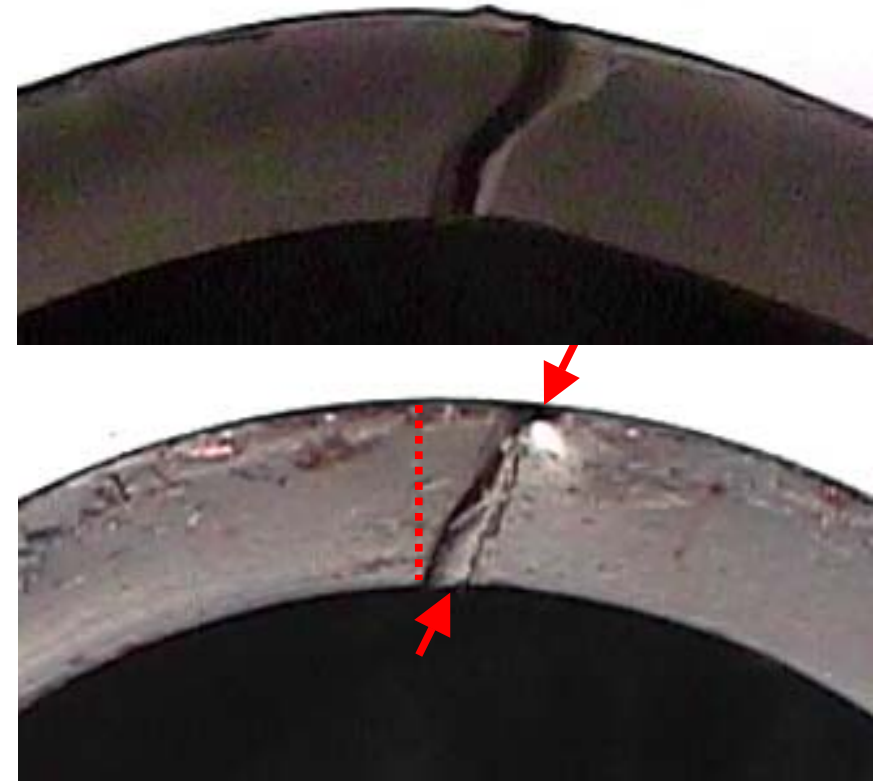

Figure 6. Cross rolling of MA956 tube via repeated passes at $900^{\circ} \mathrm{C}$. Micrographs show rolling angle $\beta=2^{\circ}$ (Top) and $8^{\circ}$ (Bottom). The red line indicates the notch as inscribed on the tube wall prior to testing. The angle between the red line and the sheared image (denoted by red arrows) gives the shear strain incurred via rotary cross-rolling process.

(top) and $\beta=8^{\circ}$ (bottom) deformation. A straight radial (dashed red line) notch was inscribed on the end of the tube wall to monitor material flow during the deformation process. The inclined image of the same notch (indicated by red arrows) provides a measure of the shear deformation induced by rotary cross rolling. We note that the sheared notch is remarkably straight for the $\beta=8^{\circ}$ rolling angle condition indicating that the shear deformation is rather uniform over the entire tube wall thickness. Shear deformation is non-uniform and confined to the middle of the tube wall section for $\beta=2^{\circ}$ rolling angle. The shear angle $(\gamma)$ was measured as $35^{\circ}$ (in Figure 6 ,
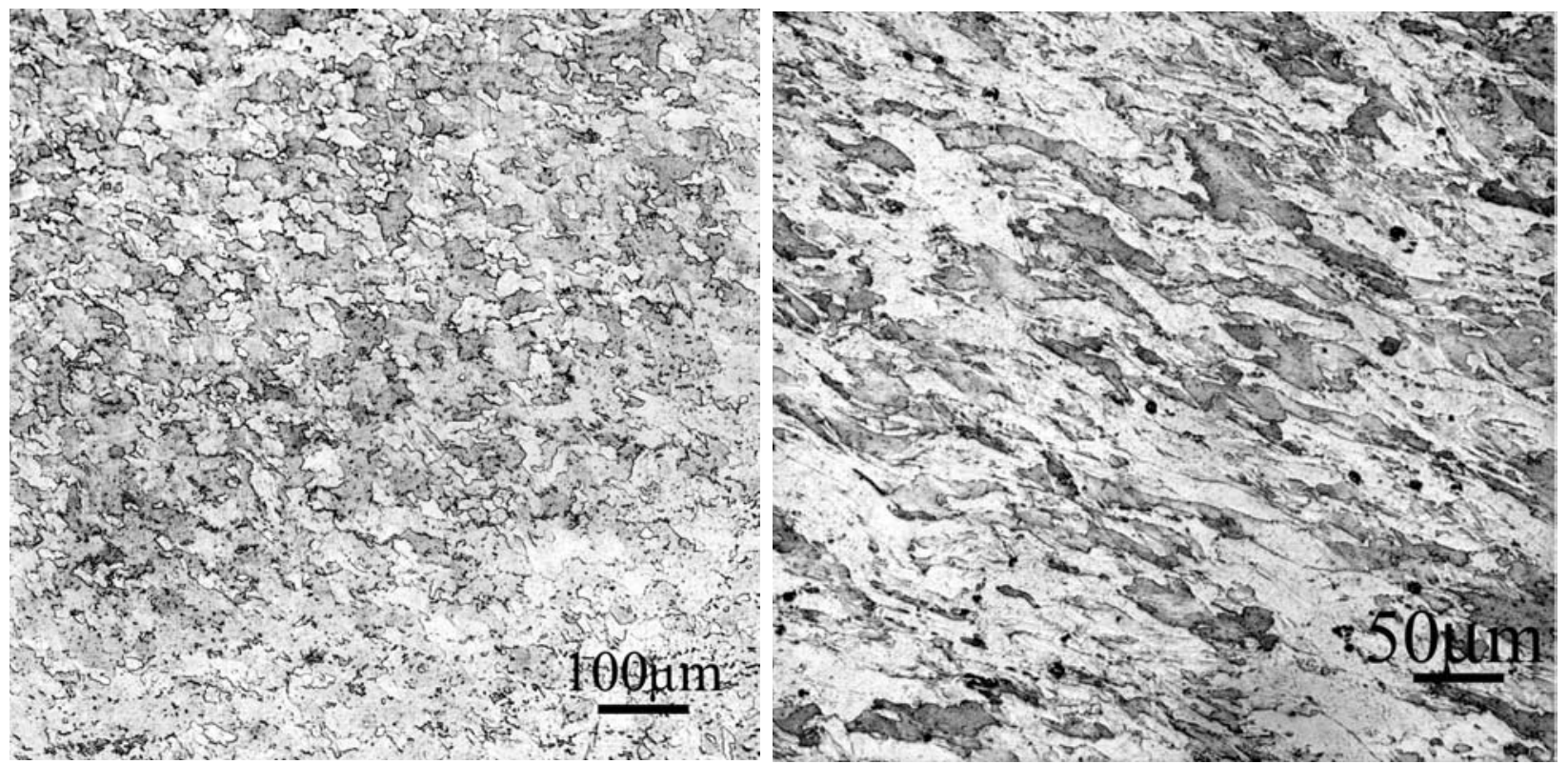

Figure 7. Cross-sectional view of a) as -received, recrystallized and b) cross-rolled and recrystallized MA956 tube $\left(\beta=8^{\circ}\right)$. The grain shape is significantly modified, with the long axis now stretched along the hoop direction. 
bottom) with a shear strain $=0.7$. Figure 7 (a), (b) show the before and after tube cross-section views indicating grain realignment under such rotary deformation. The as received extruded cross-section 2-dimesional views shows equiaxed structure, which undergoes a shape change under rotary deformation. The grains, with aspect ratio significantly greater than unity and extended in the hoop direction are deemed beneficial for hoop creep performance.

Tube samples are being flattened at $900^{\circ} \mathrm{C}$ using a combination of hot pressing and rolling. ASTM E-8 specimens are to be extracted from the entire tube wall-thickness by spark machining for hoop creep testing in Task 4.

Task 4.1: Recrystallization Annealing: Recrystallization strategies for creating abnormal grain growth in ODS alloy materials cross-rolled in Task 2.1 (and from Task 3 in later periods) suitable for transverse creep enhancements are listed in Table 1.

Table 1: Recrystallization matrix for cross-rolled ODS-Fe3Al and MA956 materials

\begin{tabular}{|c|c|c|c|c|}
\hline HT Test\# & Material & HT: Temperature, ${ }^{\circ} \mathrm{C}$ & HT: Time, Hrs & Environment \\
\hline 1 & ODS-Fe $_{3} A 1$ & $1200^{\circ} \mathrm{C}$ & $1 \mathrm{hr}$ & Air \\
\hline 2 & ODS-Fe 3 Al & $1200^{\circ} \mathrm{C}$ & $1 \mathrm{hr}$ & Argon \\
\hline 3 & ODS-MA956 & $1375^{\circ} \mathrm{C}$ & $1 \mathrm{hr}$ & Air \\
\hline 4 & ODS-MA956 & $1375^{\circ} \mathrm{C}$ & $1 \mathrm{hr}$ & Argon \\
\hline 5 & ODS-MA956 & $1400^{\circ} \mathrm{C}$ & $1 \mathrm{hr}$ & Air \\
\hline 6 & ODS-MA956 & $1400^{\circ} \mathrm{C}$ & $1 \mathrm{hr}$ & Argon \\
\hline
\end{tabular}

The heat-treatment temperatures are based on prior DOE funded work ${ }^{2-5}$ performed by the PI. The introduction of inert environment HT was initially applied to ODS-Fe 3 Al alloys ${ }^{3,8}$, which produced significant improvements in transverse creep. In the current performance period HT tests 1, 2, 3 and 5 have been completed for all cross-rolled materials from Task 2.1. Additional tests 4 and 6 are to be conducted later following a furnace overhaul.

Task 4.2: Microstructure Evaluation: Microstructures reveal elongated grain shapes in the transverse orientation for samples cross-rolled, Figure 7(b) in the transverse orientation. It is likely that surface layers are affected in rolling schedule 1 and 2 of Task 2.1 but no changes were perceptible at the level of optical resolution.
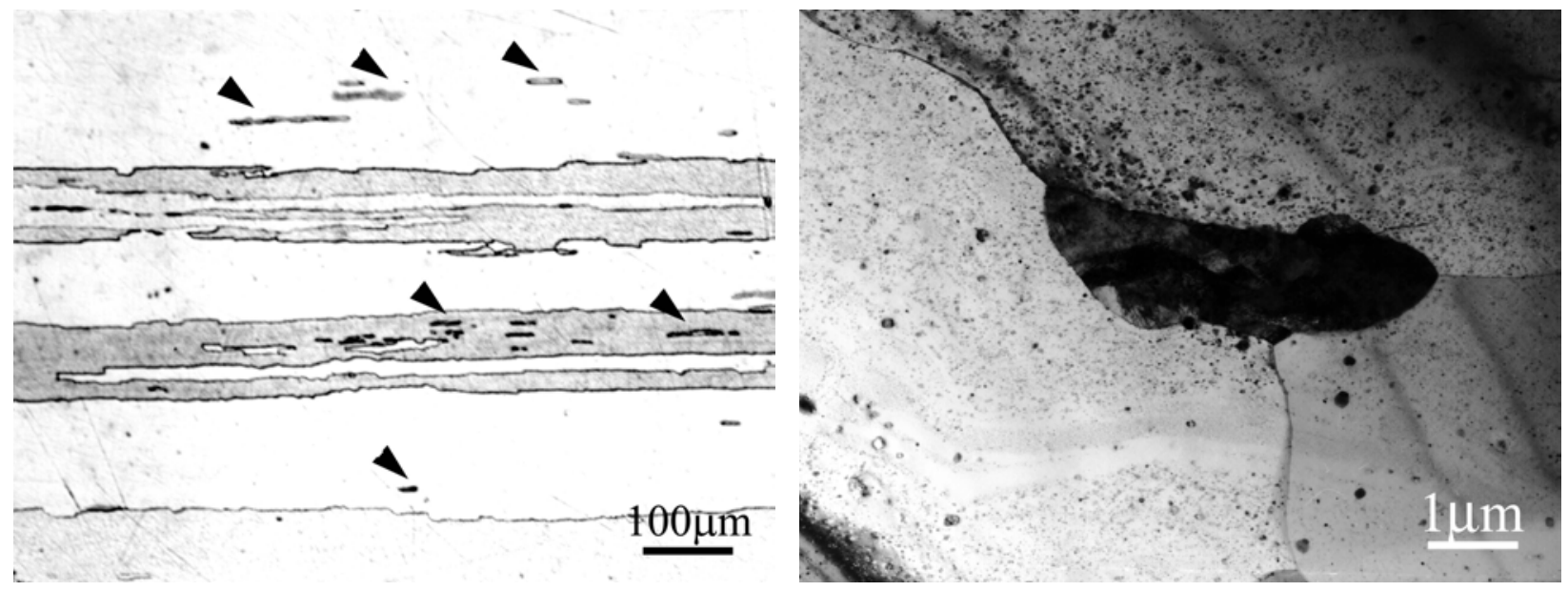

Figure 8 a) optical micrograph of as-extruded and recrystallized MA956 with a large number of unrecrystallized stringers, which are mitigated via secondary processing though b) not entirely eliminated, TEM view. 
One beneficial aspect of post extrusion processing is to mitigate the existence of unrecrystallized stingers of fine-grained material dispersed through out the matrix. Figure 8(a) shows the stringers (indicated by arrows) stretched along the extrusion axis. The strigers are normal to the hoop creep loading and consequently detrimental to hoop creep performance. Looking back to Figure 2(b) creep failure occurs by cvoid formation at grain junctions and boundaries and stringers located in the grain boundary vicinity, Figure 8(b), may be particularly susceptible. Such stringers are minimized (i.e. reduced in size and in numbers) via post processing working though not entirely eliminated. Figure 8(b) shows the remnant of such stringers in cross-rolled materials, where they exist at grain boundaries or within a single grain.

Task 4.3: Transverse Creep and Stress Rupture Response: The initial cross-rolled samples from Task 2, heat treated in Task 4.1 are spark machined to extract ASTM E-8 standard specimens from the transverse orientation. These are being evaluated in transverse creep tests initially being performed at dead load $1-2 \mathrm{Ksi}$ stresses over a temperature range of $800^{\circ} \mathrm{C}-$ $1000^{\circ} \mathrm{C}$ in air.

Figure 9 shows a typical response pattern of a MA956 cross-rolled sample (cross rolled 20\%) in creep tests. The sample exhibits a brief primary regime, an extended steady state regime (creep rate $=9 \mathrm{e}^{-5} /$ day) followed by a tertiary regime. The $y$-axis gridline spacing denotes a creep strain of $2 \%$. Note that the sample fails at an overall strain of about $3 \%$ with the largest component of strain (about 2\%) occurring in the tertiary (failure) regime. The creep life (LarsenMiller parameter) LMP $=48.87$ based on $1381 \mathrm{hrs}$ test exposure) is of the order of about $1 \%$ creep strain in the steady-state regime.

Table 2 lists selected creep data compiled for MA956 base material (Test\#

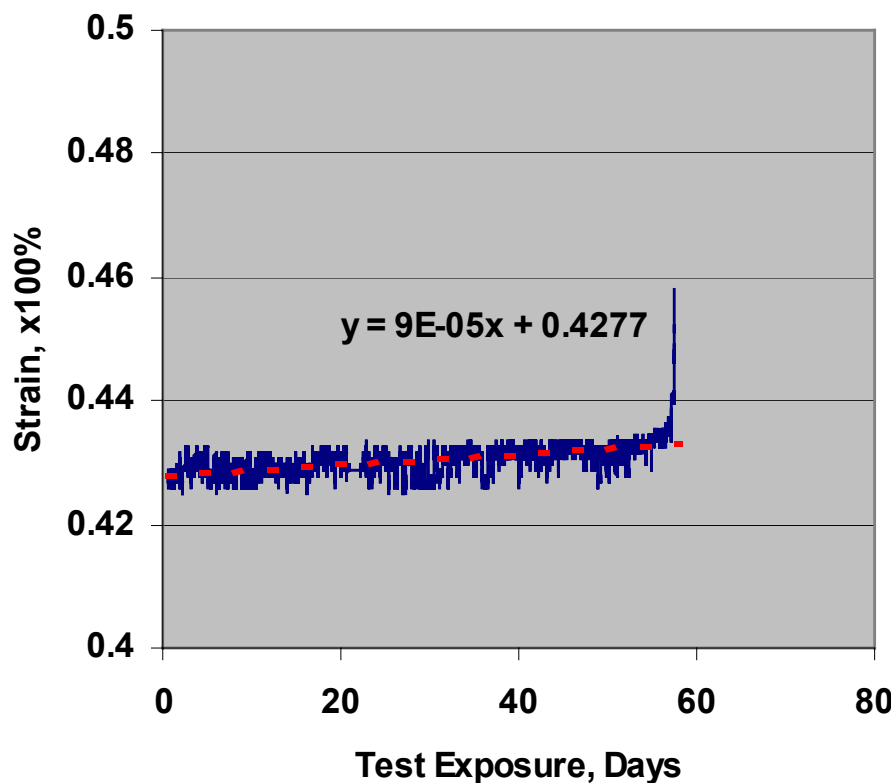

Figure 9. Creep test of a MA956 sample extracted from a $2 \frac{1}{2}$ ", OD, $1 / 4$ " wall thickness tube and cross-rolled at $900^{\circ} \mathrm{C}$ to $20 \%$ reduction. Creep test conducted at $900^{\circ} \mathrm{C}$ at $2 \mathrm{Ksi}$ stress in air. 1-3), hot cross-rolled samples (Test\# 4-7) and ambient temperature flow formed (Test\# 8-11) specimens. Samples for the base and cross-rolled conditions were extracted from the same 2 $1 \frac{1}{2}$ "OD, 1/4" wall thickness MA956 tube. Similar MA956 tubes are used for flow forming where the wall thickness is reduced $75-80 \%$ in several reducing steps at ambient temperatures. Base material tests $1-3$ were run at $900-950^{\circ} \mathrm{C}$ in air at a $1-2 \mathrm{Ksi}$ stress and the Larsen-Miller (L-M) Parameter for the base material is rather poor. In comparing tests 1-3 we note both an acute stress and temperature sensitivity in this upper limit temperature regime. For example, the creep rate at $900^{\circ} \mathrm{C}$ increases by three orders of magnitude from $2.0 \mathrm{e}^{-5}$ to $2.0 \mathrm{e}^{-2}$ when the stress is increased from $1 \mathrm{Ksi}$ to $2 \mathrm{Ksi}$, and increases by about two orders of magnitude from $2.0 \mathrm{e}^{-5}$ to $1.5 \mathrm{e}^{-3}$ as temperature is increased from $900^{\circ} \mathrm{C}$ to $950^{\circ} \mathrm{C}$. A peak value of $\mathrm{L}-\mathrm{M}=46.09$ at a mean creep-rate of $2.0 \mathrm{e}^{-2}$ was observed for test\# 1 loaded at $2 \mathrm{Ksi}$ and will be used for base comparisons. The mean creep rate/day (for tests 4-6) is estimated at $1.75 \mathrm{e}^{-4}$ with a mean Larsen Miller parameter $=$ 48.67. Thus, at least 2 orders of magnitude improvement in creep rates is achieved for the crossrolled tests in this initial evaluation. Test 7 indicates the strain rate sensitivity with respect to 
temperature. Thus strain rate drops by about 3 orders of magnitude from $10^{-4}$ range to $10^{-7}$ as the temperature is lowered from 900 to $800^{\circ} \mathrm{C}$. This test was terminated after 3400 hours as the creep-strain was observed to saturate at this temperature. Finally, tests 8-10 are creep results from flow formed specimens deformed $75-80 \%$. These flow formed tubes are slit by spark machining and flattened at room temperature and recrystallized as per the schedule indicated in Table 2. The mean creep rate is about $4.0 \mathrm{e}^{-4}$ at $900^{\circ} \mathrm{C}$ and rises to $2.6 \mathrm{e}^{-3}$ at $950^{\circ} \mathrm{C}$ and $1.1 \mathrm{e}^{-2}$ at $1000^{\circ} \mathrm{C}$. While there appears to be some scatter in the data, the test results suggest that L-M parameter is essentially similar over the $900-1000^{\circ} \mathrm{C}$ ranges and reconfirms the validity of accelerated creep tests.

Table 2. Summary of creep tests performed on cross-rolled and base MA956 alloy tubes

\begin{tabular}{|c|c|c|c|c|c|}
\hline Test & MA956 Alloy Treatment \& HT & Test Temp & Test Stress & L-M Para. & rate/day \\
\hline 1 & Flattened@900C,HT: $1375^{\circ} \mathrm{C}-1 \mathrm{hr}, \mathrm{Air}$ & $900^{\circ} \mathrm{C}$ & 2Ksi & 46.09 & $2.00 \mathrm{e}^{-2}$ \\
\hline 2 & Flattened@900C,HT: $1375^{\circ} \mathrm{C}-1 \mathrm{hr}, \mathrm{Air}$ & $900^{\circ} \mathrm{C}$ & $1 \mathrm{Ksi}$ & 48.81 & $2.00 \mathrm{e}^{-5}$ \\
\hline 3 & Flattened@900C,HT: $1375^{\circ} \mathrm{C}-1 \mathrm{hr}, \mathrm{Air}$ & $950^{\circ} \mathrm{C}$ & $1 \mathrm{Ksi}$ & 49.20 & $1.50 \mathrm{e}^{-3}$ \\
\hline 4 & CR-20\%@900C,HT: $1375^{\circ} \mathrm{C}-1 \mathrm{hr}, \mathrm{Air}$ & $900^{\circ} \mathrm{C}$ & 2 Ksi & 48.87 & $9.00 \mathrm{e}^{-5}$ \\
\hline 5 & CR-20\%@900C,HT: 1375C-1hr,Air & $900^{\circ} \mathrm{C}$ & 2 Ksi & 48.24 & $6.00 \mathrm{e}^{-4}$ \\
\hline 6 & CR-20\%@900C,HT: $1400^{\circ} \mathrm{C}-1 \mathrm{hr}, \mathrm{Air}$ & $900^{\circ} \mathrm{C}$ & $2 \mathrm{Ksi}$ & 48.89 & $1.00 \mathrm{e}^{-4}$ \\
\hline 7 & CR-20\%@900C,HT: 1400C-1hr,Air & $800^{\circ} \mathrm{C}$ & 2 Ksi & $-*$ & $6.00 e^{-7}$ \\
\hline 8 & FlowForm@RT, HT:1375º-1hr,Air1 & $900^{\circ} \mathrm{C}$ & 2 Ksi & 48.91 & $5.00 \mathrm{e}^{-4}$ \\
\hline 9 & FlowForm@RT, HT:1375C-1hr,Air1 & $1000^{\circ} \mathrm{C}$ & 2 Ksi & 48.77 & $1.14 \mathrm{e}^{-2}$ \\
\hline 10 & FlowForm@RT, HT:1375º-1hr,Air1 & $950^{\circ} \mathrm{C}$ & 2 Ksi & 48.60 & $2.60 \mathrm{e}^{-3}$ \\
\hline 11 & FlowForm@RT, HT:1375C-1hr,Air1 & $950^{\circ} \mathrm{C}$ & 2 Ksi & 49.83 & $4.00 \mathrm{e}^{-4}$ \\
\hline 12 & FlowForm@RT, HT:1375º-1hr,Air1 & $900^{\circ} \mathrm{C}$ & 2 Ksi & 49.00 & $4.00 \mathrm{e}^{-4}$ \\
\hline 13 & FlowForm@RT, HT:1375C-1hr,Air2 & $1000^{\circ} \mathrm{C}$ & 2 Ksi & 51.93 & $7.00 \mathrm{e}^{-4}$ \\
\hline 14 & FlowForm@RT, HT:1375C-1hr,Air2 & $950^{\circ} \mathrm{C}$ & $2 \mathrm{Ksi}$ & $52.01^{\#}$ & $2.00 \mathrm{e}^{-5}$ \\
\hline
\end{tabular}

${ }^{*}$ Creep tests discontinued; ${ }^{\#}$ Test continuing.

We note that ambient temperature flattening of flow-formed tubes always produced samples with some residual warp in them. In particular, some residual curvature is often observed in the gage section of the ASTM E-8 specimens in test\# 8-12 in Table 2. Ambient temperature flattening is desirable to preserve the cold-forming induced strain energy into the material to help produce a large processed grain structure. However, there was some concern that the data yielded sufficient scatter and more importantly the curvatureinduced effects were undermining or masking true material and microstructure performance. Thus, the thermo-mechanical flattening

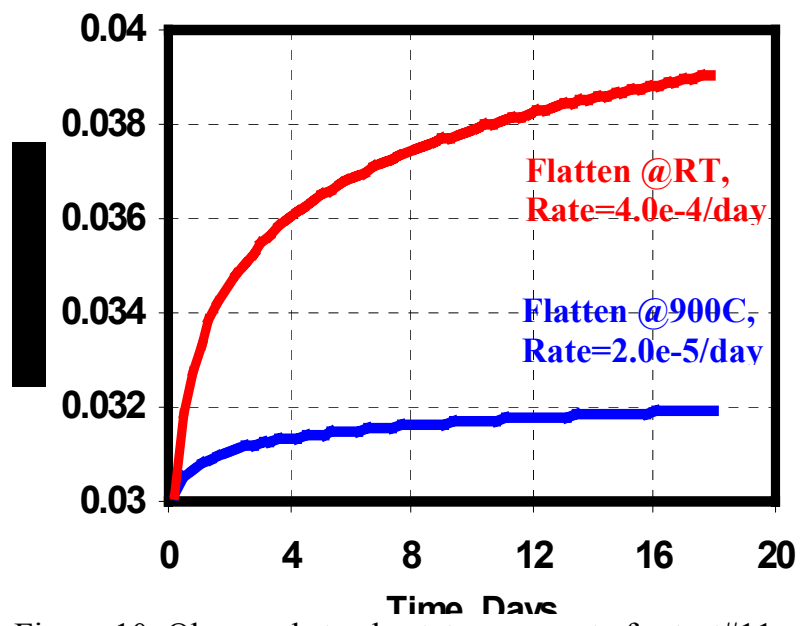

Figure 10. Observed steady state creep rate for test\#11 and 14 as a function of thermo-mechanical processing. procedure is revised and conducted at $900^{\circ} \mathrm{C}$ (labeled Air2) in parity with other rolled specimens (i.e., in tests\#1-3 and tests\#4-7). This testing phase was commenced in the previous quarters and incremental results (test\#13, 14, Table 2) are presented here. Figure 10 illustrates the effect of thermo-mechanical treatment of flattening at room temperature versus $900^{\circ} \mathrm{C}$ on ensuing creep rate. Sample flattened at room temperature (test\#11 as depicted) exhibits both a higher primary 
creep strain as well as a higher creep rate in the steady state regime than a corresponding sample falttened at $900^{\circ} \mathrm{C}$ (test $\# 14$ ). The primary strain may be somewhat exaggerated because of the initial warping in the test specimens. Test 13 was completed in the previous quarter. Test 14 has been resumed following the creep rig upgrade and continues till date. The LMP value for test\#14 exceeds that recorded for test\#13. Additionally tests will be conducted at $1050^{\circ} \mathrm{C}$ to consolidate this performance expectation for flow-formed MA956 materials.

This revised flattening and recrystallization (HT2) scheme provides considerable gains in hoop creep enhancement. The revised HT specimens are being tested at more aggressive 950$1000^{\circ} \mathrm{C}$ range and comparisons only possible at $950^{\circ} \mathrm{C}$. For example, the measured creep rate is $1.50 \mathrm{e}^{-3} 1.5$ for base material (test\#3 at $1 \mathrm{Ksi}$ stress), $4.00 \mathrm{e}^{-4}$ for flow-formed HT1 and $4.00 \mathrm{e}^{-5}$ for flow-formed HT2 treatments. The base material LMP $=46.09$ has now been improved to 52.01.

\section{$\S$ 4. Results and Discussion}

Significant grain alignment was recorded (Task 2.1. cross-rolling of flat MA956 samples) in the transverse direction for samples cross-rolled 20\%. In the initial rotary cross rolling of MA956 tube samples we note a similar material flow in the circumferential direction as illustrated macroscopically in Figure 6 and microscopically in Figure 7. Secondary deformation processes also seem to mitigate the occurrence of unrecrystallized fine-grained stringers, Figure 8(a), (b) that are extremely detrimental to hoop creep performance. We anticipate the material flow imposed in cross rolling and flow forming also acts to realign the remaining stringers in the hoop direction where there impact on creep void formation at these junctions can be mitigated as well.

This shear deformation and its precise characteristics across the wall thickness of the tube are process dependent. This shear is surprisingly uniform across the tube wall thickness at $\beta=8^{\circ}$ and very non-uniform at $\beta=2^{\circ}$ cross rolling angle. The leading direction of the tube was not precisely tracked between passes, and it is unknown if this affects the results as well. Nonetheless, the uniform shear observed at $\beta=8^{\circ}$ across the tube wall thickness illustrates the uniformity of the rotary rolling process under proper and well defined process parameters. The installation of an in-house rotary rolling apparatus at UCSD has been accomplished. The increased deformation capacity, on account of the larger power source, assures that materials can be rotary cross-rolled at ambient temperatures. This is beneficial in order to preserve the deformation strain energy that could produce large grains during its release upon recrystallization

Our initial intent was to compile creep data on cross-rolled samples to be compared to base data generated at ORNL. However, reference MA956 data from ORNL was compiled form samples with a different processing history. In an effort towards uniformity we are compiling our own base hoop creep data for $2 \frac{1 / 2}{2}$ OD, $1 / 4$ " wall thickness tubes. In task 4 , we have evaluated the performance of flat MA956 cross-rolled $20 \%$ that is deemed about 2 orders of magnitude better than the base reference samples in creep rates. The flow formed creep results obtained in the current performance period seem to have some scatter perhaps due to the residual curvature in the room-temperature flattened specimens. On occasion such specimens exhibited large creep rates (for example test\# 10). Results from flow formed materials recrystallized under the revised heat treatment (HT2) exhibit further hoop creep enhancement till date suggesting that optimum effects may be achievable via increased deformation strains. Furthermore, it appears that a $900^{\circ} \mathrm{C}$ flattening treatment may not be detrimental as previously anticipated. This result is expected to modify our processing path selection as the baseline MA956 tube material LMP $=46.09$ has been improved to over 52.00 in hoop creep testing. Such hoop creep performance in MA956 tubes beyond all previous results and has been demonstrated for the first time in this program. 


\section{§ 4. Conclusions}

The current research program is concluding its tenth quarter of performance. The project progress is on schedule with work continuing in Tasks 2-4. MA956 tubes have been successfully rotary cross-rolled while inducing significant and near uniform shear strain across the tube wall thickness under appropriate conditions. The grain shape changes and realignment are consistent with prior evidence for the flat cross-rolled samples. We also note the mitigation of fine-grained stringers that can affect hoop creep rather significantly.

Creep tests of post processed samples both in the high temperature laboratory cross-rolling as well as the ambient temperature flow forming illustrate their significantly enhanced creep response in terms of creep rate/day as well as overall Larsen-Miller parameter when compared to base samples. This is the original predicate of our proposed program now being realized in practice. Thus, post-processing methods may be employed to improve the vendor-supplied material. Test results on flow formed MA956 (reduced $75-80 \%$ in wall-thickness) indicate that the creep performance is significantly enhanced at larger deformation strains. This beneficial improvement is considerably larger than that achieved in cross-rolled samples deformed only $20 \%$ and is statistically significant. Contrary to earlier belief, present result suggests that while the beneficial effects of grain shape control may become apparent and achievable at low levels of deformation strain, these effects can be improved upon with incremental deformation up to $80 \%$. We note that flow-formed materials are very thermo-mechanical processing path sensitive.

The creep rig hardware retrofit has been completed in early 2006 and the furnaces are being brought on line sequentially. A concerted data collection regime is now underway at temperatures of $1000^{\circ} \mathrm{C}$ and above. Such accelerated testing will shorten the individual test duration and allow additional tests to improve overall creep data statistics.

\section{References:}

1. F. Starr, in Materials for High-Temperature Power Generation and Process Plant Applications, A. Strang, Ed., IOM Communications Ltd., Book No. 728, pp. 79-152 (2000).

2. V.K. Sikka, I.G. Wright, and B.K. Kad, " Processing of Oxide-Dispersion-Strengthened $\mathrm{Fe}_{3} \mathrm{Al}-\mathrm{Based}$ Alloy Tube" (1998) $12^{\text {th }}$ Annual Fossil Energy Materials Conf., Knoxville, TN, May 12-14, 1998, p.11-19

3. B.K. Kad, C.G. McKamey, I.G. Wright and V.K. Sikka, "Optimization of ODS-Alloy Properties" (2002) $16^{\text {th }}$ Annual Fossil Energy Materials Conf., Baltimore, MD, April $22^{\text {nd }}-24^{\text {th }}, 2002$.

4. B.K. Kad, C.G. McKamey, I.G. Wright and V.K. Sikka, "High Temperature Mechanical Properties of ODS-Fe ${ }_{3} \mathrm{Al}$ Tubes" (2001) $15^{\text {th }}$ Annual Fossil Energy Materials Conf., Knoxville, TN, April $30^{\text {th }}$-May $2^{\text {nd }}, 2001$

5. B.K. Kad, V.K. Sikka, R.N. Wright and I.G. Wright, "Oxide Dispersion Strengthened $\mathrm{Fe}_{3} \mathrm{Al}-\mathrm{Based}$ Alloy Tubes" (2000) $14^{\text {th }}$ Annual Fossil Energy Materials Conf., Knoxville, TN, April 24-26, 2000; ibid (1999) $13^{\text {th }}$ Annual Fossil Energy Materials Conf., Knoxville, TN, May $11^{\text {th }}-14^{\text {t }}, 1999$.

6. J. Ritherdon, A.R. Jones and I.G. Wright, "The Recovery and Recrystallization of a Mechanically Alloyed ODS-Fe ${ }_{3}$ Al Alloy” (2001) Materials Science Forum, 360-362, pp.217-222, 2001

7. I.W. Chen and A.S. Argon, "Creep Cavitation in 304 Stainless Steel" (1981) Acta Metallurgica, 29, p.1321, 1981; ibid. "Diffusive Growth of Grain-Boundary Cavities" Acta Metallurgica, 29, p1759, 1981

8. B.K. Kad, I.G. Wright, V.K. Sikka and R.R. Judkins, (2004) "Optimization of Hoop Creep Response in ODS-Fe 3 Al Tubes" $18^{\text {th }}$ Annual Fossil Energy Materials Conf., Knoxville, TN, June $2^{\text {nd }}-4^{\text {th }}, 2004$

9. T.Z. Blazynski, "Metal Forming - Tool Profiles and Flow" Macmillan Press, NY, 1976 